\title{
I.T. Infrastructure Event Management System
}

\author{
August Anthony N. Balute \\ Emilio Aguinaldo College \\ Manila, Philippines \\ CAP College Foundation Inc. \\ Makati, Philippines
}

\author{
Dennis B. Gonzales, PhD \\ University of the East \\ Manila, Philippines
}

\author{
Mary Ann C. Paguio, PhD \\ HCT-IT, Muscat, Oman
}

\begin{abstract}
Since the dawn of the computing age, processes had been automated. It paved the way to ease manual resolution of technical outages. Although, technology is vastly dominating the globe, its development remains to be dynamic. This study aims to refine the efficiency of existing event management process and to develop a system to manage incident tickets. The researcher collected the data through face to face interviews, observations and questionnaires to event management members and resolving team for Fidelity Information Services. Queries are regarding classification of incident tickets, data security and the reliability of the proposed system. Based on the study conducted, the event management department needs a more efficient system to manage such incidents. To address this, the researcher devised a new tool for the department to uplift their standard processing for incidents. The system will also be significant not only to the Fidelity Information Services but to other Industrial firms as well. System outages and transaction incidence will be addressed properly and timely which reduces business cost for clients. Therefore, this study will benefit not only the companies but the clients as well.
\end{abstract}

\section{Keywords}

Event, incident, guidelines, questionnaires, Service Level of Agreement

\section{INTRODUCTION}

In prior years an intersection purpose of circumstances has driven Information Technology capacities to end up in more association procedures engineered so they can be better adaptable and customization to the business centers of a couple of different business affiliations. The illustrations of these IT limits join the headway of additionally convincing and capable ways and means for relationship to serve their client people and other private endeavors with a particular deciding objective to pass on more improved and better organizations; the developing reliance on IT for the closer steady checking of the affiliations' data to bolster missionkey exercises; the need for upgraded reporting basic to meet stricter legitimate necessities; and all the all the all the more asking for sales from clients and senior association for working up a more lifted measure of flexibility and the decreased of disappointment in the IT foundation. The IT Service Management (ITSM) model discusses a viewpoint change for IT limits as it de-focuses on the association of IT resources and spotlights on the acquisition of worth end-toend IT associations. While there are different avenues for IT capacities to complete such changes, a large portion of change has picked the IT Infrastructure Library (ITIL) structure to give more basic execution and course of the essentials required by the affiliation and a run of the mill tongue of correspondence between the affiliation and the clients it serves. IT (Information Technology) divisions are the most complex parts of associations in which Information
Innovation Infrastructure Library (IIIL), saw as the most by and large used IT structure, is a part of these divisions. This standard is accepted anticipated that would support IT units of relationship to execute quality-based systems with the deciding objective to improve the way of IT organizations. On the same plane, ITIL itself is included five areas, specifically: organization method, organization diagram, organization operation, organization move and constant organization change. Every one of these parts has a couple of systems. The structure of every one of ITIL techniques joins definition, purpose of interest depiction, Critical Success Factors (CSFs) and Key Performance Indicators (KPIs).One of the fundamental ITIL procedures is Problem Management process. This framework addresses issues to see rout purposes behind reported scenes and endeavors to hurl them. In this paper, all KPIs connected with this strategy were at initially gathered with some mechanical issues experienced which were from there on isolated into sub parts to make measures in recognizing these using the most comprehensively saw KPIs and practices.

KPIs or KSIs, help an association to characterize and measure progress towards hierarchical objectives. Note ought to be taken that those KPIs ought to be settled upon by an association's supervisor to choose and attract an arrangement preceding usage. Directors typically select these KPIs in light of their business destinations. Accordingly, chose KPIs must mirror the hierarchical objectives. Through their prefix name (key), it is apparent that there must be a key to authoritative accomplishment as it is quantifiable and mirrors the present circumstance of that specific procedure. Key execution markers ordinarily are long haul contemplations for an association as these give some potential instruments to think of a full grown procedure toward the end of the arrangement.

\section{LITERATURE REVIEW}

Receiving an IT Infrastructure Library (ITIL) system as way to deal with actualize a structure of best practice and direction for IT administration underpins the factual environment according to Losco [1].The essential goal of ICT administration is to guarantee that the IT administrations are adjusted to the business and factual needs and effectively bolster them. It is basic that the IT administrations support the business and measurable procedures, yet it is likewise progressively critical that IT goes about as operators for change to encourage business change and factual advancement. This methodology is key to accomplish business profits by IT at a concurred and controlled cost additionally in the factual association. Without great IT administration, it is basic for IT anticipates falling flat or going well over spending plan at venture state, for progressing expenses of proprietorship to winding crazy, and for measurable procedure to neglect to accomplish the normal advantages. ITIL's worth suggestion, received by Istat, fixates on IT administration supplier comprehension client's business targets and needs and the part that IT 
administrations play in empowering these destinations to be met.

As Walker [2] stated that the goal of the Incident Management Process is to return IT administrations at Flinders University to ordinary administration levels (as characterized in Service Level Agreements), as fast as could be expected under the circumstances with least interruption to college partners. The Incident Management Process guarantees that a record of episodes is kept for reporting purposes and incorporated with different procedure, for example, Problem Management, to drive ceaseless change. The recording of episodes gives a chance to gain from occurrences and for zones of danger and control insufficiencies to be distinguished when an episode happens. Administration Ownership is a basic segment to guaranteeing the nature of administrations gave by IT. The Service Owner must be assigned for every support of be overseen by the Problem Management process. The Service Owner attempts to guarantee that any Problem that might affect their administration is controlled. Data Technology Infrastructure offices are the most complex parts of associations and ITIL is viewed as the most broadly utilized IT structure as a part of them. This accepted standard is planned to bolster IT units of associations to actualize quality based procedures with an end goal to enhance the nature of IT administrations. ITIL, itself comprises of five parts which are administration system, administration plan, administration operation, administration move and persistent administration change. Each of these parts has a few procedures. The structure of each one of ITIL procedures incorporates definition, point of interest portrayal, Critical Success Factors (CSFs) and Key Performance Indicators (KPIs). Then again, the Control Objectives for Information and related Technology (COBIT) is a review and ITconstruct system with high ability in light of procedure estimation. [3].

It is also supported by the study of Richardson and Ahmed [4] that organizations, developing and develop, require the capacity to rapidly resolve and oversee occurrences and changes to their IT base, resources, and setups. IT associations are searching for a BSM arrangement that offers a coordinated, robotized, and driving - edge approach that additionally guarantees a high caliber of administration to their business. Moreover, they need an answer conveyed without the regular high usage cost and time. Notwithstanding understanding the necessities of the IT associations, BMC Software needs to adjust IT to the business objectives. In any case, to pick up the focused edge and remain the BSM market pioneer, BMC Software needs to likewise proceed with the legacy of securing innovation arrangements that meet its BSM technique since BMC Software does not have the in-house asset ability to create BSM arrangements in a short time span. Being first to advertise with strong IT arrangements (not items) in the BSM innovation region to comprehend IT difficulties is a prerequisite for IT administration programming organizations.

The incident management process according to Nuit [5] incorporates the coordination of administration recuperation, warning, heightening, and occasion survey for all administrations as characterized in the Northwestern University Information Technology (NUIT) Service Catalog. This report is proposed to give high- level outline of the episode administration work process. This archive is to be utilized as reference for all NUIT staff to unmistakably comprehend the gauges and methods put set up to deal with an episode through administration rebuilding and occurrence survey.

The article about Management Information Management Department accentuates that the Information and Communications Technology Support Information System (ICTSIS) will help in the MISD's capacity of rendering ICT bolsters Services. It will serve as an electronic ICT administration helpdesk available for all CFO workers everywhere throughout the nation. Workers can report and/or demand for ICT related administrations, report an episode, follow up on ICT ask for, and so on. MISD staff can likewise log their ICT reports in the framework. The framework is relied upon to create information on the status of ICT gear, permit close, accessible IP addresses, and most normal ICT issues among others. The most common way to control access to the proposed system is still with the use of a username and password. But a password is only as secure as the person holding it. They are to secure and protect the confidential, important information or document of the organization or company. Best mentioned the accompanying objective facts about the PC and project journalists it has been said that the PC commits no errors; however the system authors do commit errors and any bearings given to the PCs are reliably executed. The PC doesn't think; it can just execute the bearings of a reasoning individual. In the event that poor information or defective projects are brought into the PC, the information examination will prompt invalid conclusions. This expression is "Junk out. Waste in" depict the issue entirely well. Another important social issue in information systems involves privacy. Basically, the issue of privacy deals with the collection and use or misuse of data. Integrity of data is the primary concern.

In the book of securing intellectual Property: Protecting Trade Secrets and Other information Assets [6] best mentioned the accompanying objective facts about the PC and project journalists it has been said that the PC commits no errors; however the system authors do commit errors and any bearings given to the PCs are reliably executed. The PC doesn't think; it can just execute the bearings of a reasoning individual. In the event that poor information or defective projects are brought into the PC, the information examination will prompt invalid conclusions. This expression is "Junk out. Waste in" depict the issue entirely well. With the utilization of the proposed framework, episode ticket data turns out to be more classified and safe in light of the fact that the data is shared just inside of an association. Secrecy of information is one approach to secure the data uprightness of the clients and the organization. To secure as well as to secure information crosswise over changing and sharing data.

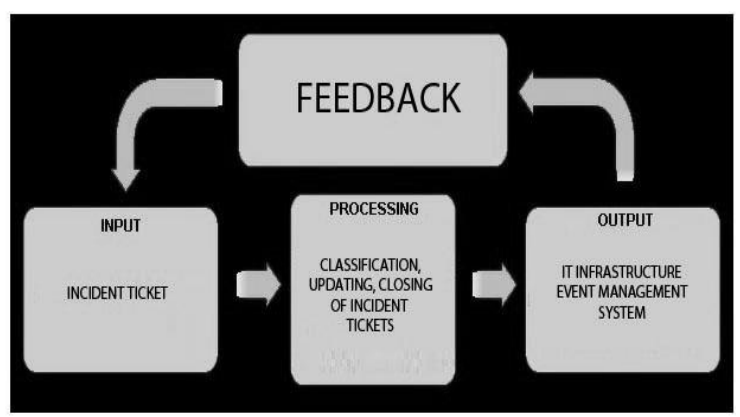

Figure 1- Conceptual Framework 
This diagram provides a graphical view on the conceptual structure of the proposed system. This process will manage incident issues within the organization infrastructure. The system will classify depending on its priority if it is high or low. This proposed system will also set the level of access of its users and has a capability to adjust the restriction or process depending on organization requirements.

\section{METHODOLOGY}

The purposive method of research will be used in this study. The main goal of purposive sampling is to focus on particular characteristics of a population that are of interest, which is more effective to answer the research questions.

According to Brink [8], purposive sampling requires selecting participants who are knowledgeable about the issue in question, because of their sheer involvement in and experience of the situation.

While Creswell [9] states that purposive sampling refers to selection of sites or participants that will best help the researcher understand the problem and the research question, they must be willing to reflect on and share this knowledge. In this occurrence, the best inspecting technique to utilize is Total Population Sampling. TPS is a system where the whole populations that meet the criteria like specific skill set and experience are incorporated into the research being led. Total Population Sampling is all the more ordinarily utilized where the quantity of cases being examined is Relatively Small.

Likert Scale. In the interpretation of the Weighted Mean (WM), Likert's Scale method has been used by the proponent using the following intervals and verbal interpretations.

$\begin{array}{lll}\text { Verbal Interpretation } & \text { Scale } & \text { Range } \\ \text { Strongly Agree (SA) } & 5 & 4.50-5.00 \\ \text { Agree (A) } & 4 & 3.50-4.49 \\ \text { Neutral (N) } & 3 & 2.50-3.49 \\ \text { Disagree (D) } & 2 & 1.50-2.49 \\ \text { Strongly Disagree (SD) } & 1 & 1.00-1.49\end{array}$

\section{Figure 2- Likert Scale}

Five point Likert scale was mostly recommended from previous studies K. Jansen, K. Corley, B. Jansen [10] Respondents were requested that react to the things by demonstrating their level of assertion utilizing a five-point Likert scale. five-point Likert scale utilized in light of the fact that this sort of scale can make a tradeoff between the clashing objectives of offering enough decision since just a few choices means measuring just bearing instead of additionally quality of conclusion and making things reasonable for respondents. This section gives a concise description of the methods used in developing a system. The proposed system is developed using Evolutionary Prototyping based methodology.

According to Walker [11] Prototyping addresses these issues with an iterative or winding procedure, in which a less difficult model is persistently refined toward the sought end. Essentially, prototyping comprises of a progression of stages in which a model is talked about and refined by the partners, and afterward actualized by the engineers. At that point the following stage takes after the same example, yet with a somewhat more definite model. A model begins essentially and develops in multifaceted nature. All partners, administrators, clients, designers, specialists, and so forth are incorporated from the start and at all levels of advancement. The point is to cooperate to understand the regular goal and minimize misconception and exclusions. The philosophy highlights adaptability to suit switch straight up until the item is finished.

Prototyping depends on building a model of a framework to be created. Besides, the underlying model ought to incorporate the real program modules, the database, screens, reports, and the inputs and yields that the framework will use for speaking with other (interfacing) frameworks. A model as a false up is significant. With the Prototyping Methodology, despite the fact that a model might be minimal more than a counterfeit up when it is first fabricated, it turns into the first of its kind when it is done. Along these lines, when the prototyping process closes, the model has turned into the framework. Particular sort of model will be utilized as a part of framework improvement which is transformative models since it advances into the last framework through iterative fuse of client input.

The figure below shows the process of Evolutionary Prototyping Model; (1) Design, (2) Build Prototype, (3) User test prototype, (4) Feedback provided, (5) Refine prototype, (6) Final Product

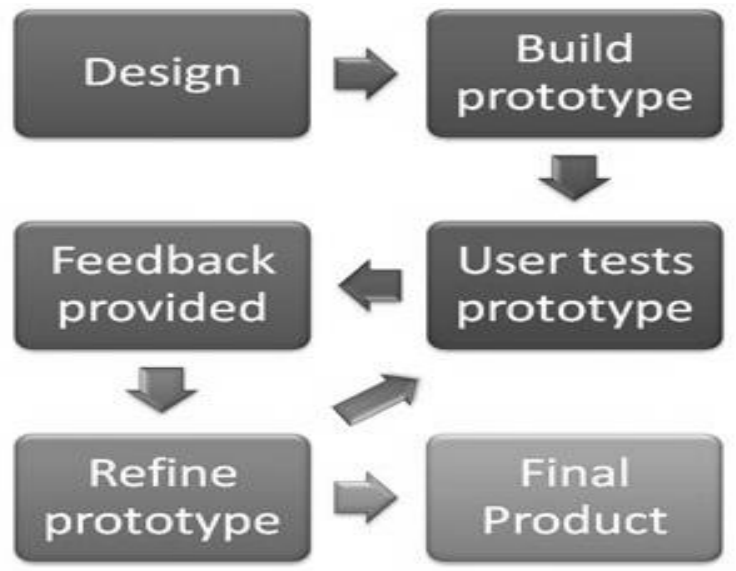

Figure 3- Prototyping Methodology

This is the place the specialized outline of the framework is made by: 1.) planning the specialized framework engineering - picking a configuration that will best suit the association's framework and future needs, and 2.) planning the frameworks model - graphically making a model from graphical client interface (GUI), GUI screen configuration, and databases, to position of articles on screen. This likewise incorporates the accompanying exercises: 1.) constructing the specialized framework engineering - utilizing a fitting programming dialect to assemble the framework, and 2.) fabricating the database and projects - the IT masters compose programs which will be utilized on the framework. The proposed system is developed using Prototype methodology. This method of software development was chosen due to the time constraints of a capstone project and the approach of producing the most quality in lesser amount of time and resources. The proponent presented the use of System Prototype and use case diagram. 


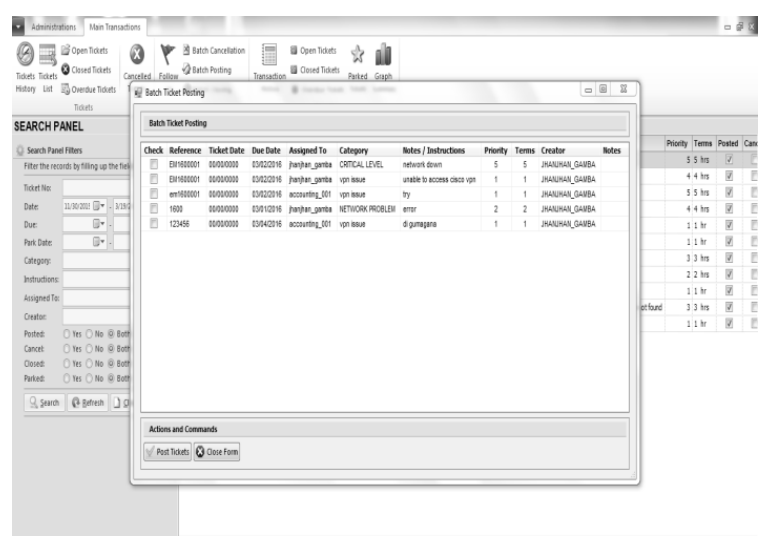

Figure 4- System Prototype

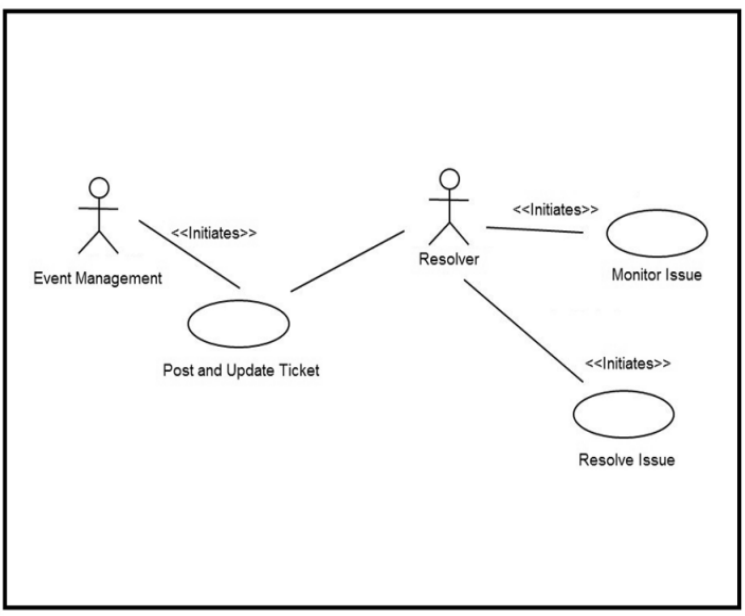

Figure 5- Use Case Diagram

The study created the questionnaire based on the general objectives and specific objectives of the study. The initial instrument has five (5) parts. The first part was the issue encountered in the existing process. The second part was the issue encountered in terms of high priority. The third part was the issue encountered in terms of low priority. The fourth part was the performance of the proposed system in terms of generation of reports. The last part was performance of the proposed system in terms of user level of access. There were twenty six (26) questions in the questionnaire. It aimed to determine the proposed system if it is acceptable to the stakeholders. The stakeholders could respond using a rating scale (1 - Strongly disagree to 5 Strongly agree).

Table 2- Existing Problems

\begin{tabular}{|ll|c|}
\hline \multicolumn{1}{|c|}{ Indicator } & $\begin{array}{c}\text { Weighted } \\
\text { Mean }\end{array}$ \\
\hline 1. & $\begin{array}{l}\text { Classification of Incident tickets is } \\
\text { time consuming. }\end{array}$ & 4.93 \\
\hline 2. & $\begin{array}{l}\text { Creating a notification and sending } \\
\text { update is time consuming }\end{array}$ & 4.58 \\
\hline 3. & $\begin{array}{l}\text { Lack of database to store incident data } \\
\text { which leads to loss and alteration of } \\
\text { data }\end{array}$ & 4.86 \\
\hline 4. & \begin{tabular}{l} 
Duplication of incident tickets \\
\hline 5.
\end{tabular} & $\begin{array}{l}\text { Gathering the necessary information } \\
\text { from resolving team is very tedious }\end{array}$ \\
\hline
\end{tabular}

\begin{tabular}{|c|c|c|}
\hline 6. & No generation of reports for future use & 4.51 \\
\hline 7. $\begin{array}{l}\text { Security of information system and } \\
\text { information usage }\end{array}$ & 3.72 \\
\hline & \multicolumn{2}{|c|}{ Average Weighted Mean } \\
\hline
\end{tabular}

As indicated in Table 1, it reveals that among the indicators pertaining to the problem encountered, ranked one is "Classification of Incident tickets is time consuming" with a weighted mean of 4.93 interpreted as "Strongly Agree", followed by "Lack of database to store incident data which leads to loss and alteration of data." in rank two with a weighted mean of 4.86 interpreted as "Strongly Agree" followed by "Duplication of incident tickets" in rank number three with a weighted mean of 4.79 interpreted as "Strongly Agree", followed by "Creating a notification and sending update is time consuming." in rank four with a weighted mean of 4.58 interpreted as "Strongly Agree", followed by "No generation of reports for future use." in rank five with a weighted mean of 4.51 interpreted as "Strongly Agree", followed by "Gathering the necessary information from resolving team is very tedious." in rank six with a weighted mean of 4.43interpreted as "Agree" and "Security of information system and information usage." in rank seven having the weighted mean of 3.72 which is verbally interpreted as "Agree". This criterion manifests that there is a need for a more functional event management system software.

Wells [7] Keep things simple and resist the urge to overengineer: implement the most cost effective technology. The automation technology chosen should be reliable, straightforward to use, and easy to repair and maintain. Preference should be given to equipment with as much flexibility built into it as possible to allow for future upgrades or alternative applications.

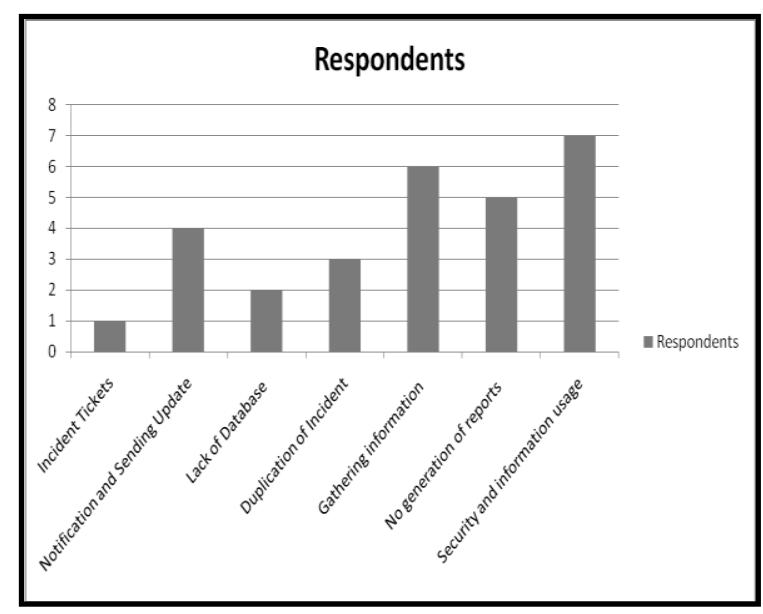

Figure 1- Respondent Results - Existing Problems

In Figure 1, it demonstrates the number of respondents answering the problems encountered in the existing system. From the 7 indicators, more respondents are answering in indicator no. 7 , because the user wanted to have more secured in terms of using the system and information usage. 


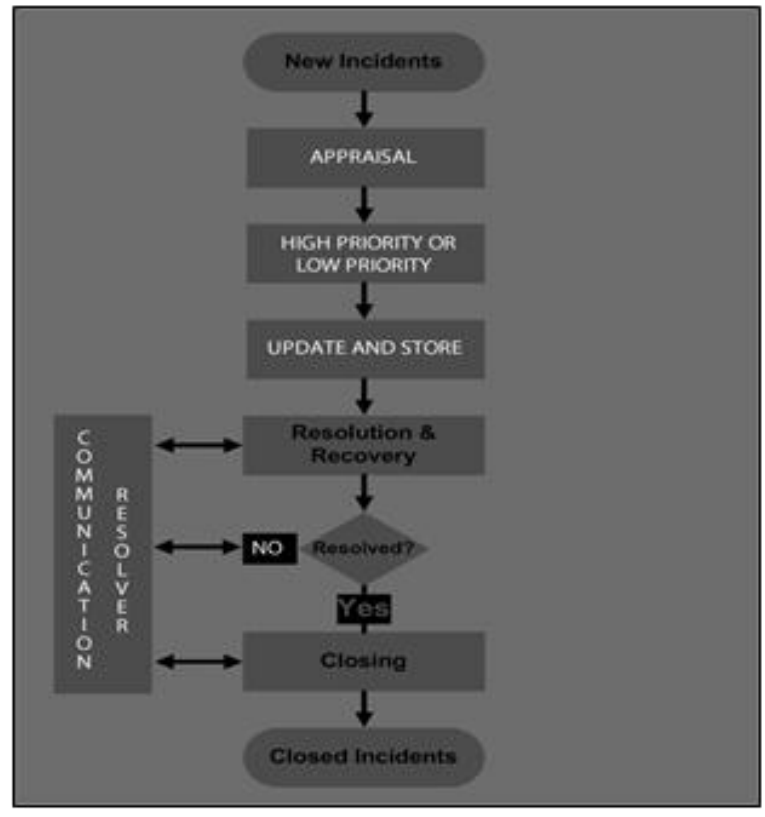

Figure 2 - System Flowchart

Figure 2 shows the proposed process or solution model to a given problem. New incident ticket is obtained from outlook, appraised and manually classified, updated and stored. Communicate from the resolver team until the issue is resolved. The staff determines if the incident is ready for closure. When the incident gets closed the event management informs the client and event management sends a report to resolver team.

\section{RESULTS}

As presented, in Table 2 as shown below, the summary of results of evaluation of Event Management Respondents on the Event Management System yielded the following values: Event Management Respondents rated, Incident Priority Level (High) 4.46, Incident Priority Level (Low) 4.58, Generation of Incident Reports 4.84, and Administration of User Level of Access4.66. This value yielded an overall weighted mean of 4.64 verbally interpreted as "Strongly Agree" (SA).

This means that the Information Technology Infrastructure Event Management System is strongly agreeable to the majority of respondents.

\section{Table 2 - Summary Of Results}

\begin{tabular}{|c|c|c|}
\hline Indicator & W. M. & R \\
\hline $1 . \quad \begin{array}{l}\text { Incident Priority Level } \\
\text { (High) }\end{array}$ & 4.46 & 4 \\
\hline $2 . \quad \begin{array}{l}\text { Incident Priority Level } \\
\text { (Low) }\end{array}$ & 4.58 & 3 \\
\hline $3 . \quad \begin{array}{l}\text { Generation of Incident } \\
\text { Reports }\end{array}$ & 4.64 & 1 \\
\hline $4 . \quad \begin{array}{l}\text { Administration of User } \\
\text { Level of Access }\end{array}$ & $\mathbf{4 . 6 4}$ & \\
\hline \multicolumn{2}{|l}{ Overall Values } & \\
\hline
\end{tabular}

\section{DISCUSSION}

The main role of this study was to outline and build up a framework: Information Technology Infrastructure Event Management System for Fidelity Information Services for the Event Management Department of Fidelity Information Services that answered the following objectives:

1. To determine the problem encountered with the existing Information Technology Infrastructure Event Management System.

2. To evaluate the Incident ticket in terms of the following:

\subsection{High priority, and}

2.2. Low priority

3. To assess the Performance of the proposed Information Technology Infrastructure Event Management System in terms of the following:

\subsection{Reports Generation \\ 3.2. User Level Access Administration}

The proposed system has answered the general objective and the specific objectives of the study with the help of questionnaires, interviews, observation and statistical tools. This implies that the respondents of the study believed that the Information Technology Infrastructure Event Management System is highly acceptable to be used in Event Management Department of Fidelity Information Services.

\section{CONCLUSION, RECOMMENDATION AND FURTHER RESEARCH}

Based on Event Management Member comments on final testing, the respondents are already positive and satisfied with the reliability, security, functionality of the system. The researcher found out that this system met the objective of the study. The procedures and methods on the proposed system were evaluated "Strongly Agree". The development of the Information Technology Infrastructure Event Management System for Fidelity Information Services system was successful.

Derived from the findings and conclusions of the study are the following recommendations:

1. The developed program may be used as an effective software for managing the Event Management Tickets in Event Management department in Fidelity Information Services.

2. There should also another study about Event Management Process for the benefit of Incident Management Members for better improvement and hitting Service Level of Agreement.

\section{REFERENCES}

[1] S. Losco (2014), "The ICT Change Management at Istat", Available https://www.unece.org/fileadmin/DAM/stats/documents/e ce/ces/ge.50/2014/Topic_1_Italy.pdf

[2] R. Walker (2013), "IT Incident Management Framework \& Procedure", Available at http://www.flinders.edu.au/isdfiles/documents/CSC\%20form\%20library/IT\%20Incident $\% 20$ Management $\% 20$ Framework $\% 20 \& \% 20$ Procedure $\% 2$ 0V\%201_2.pdf 
[3] M. Sharifi (2011), "The Most Applicable KPIs of Problem Management Processing Organizations", Available at http://ijssst.info/Vol-10/No-3/paper8.pdf. Universiti Teknologi Malaysia , 10 (3), pp. 77-78

[4] B.F. Richardson \& Y.M. Ahmed (2011), "Aligning Business Service Management to Goals: An Integrated Approach at BMC Software", Available at http://www.aabri.com/manuscripts/10620.pdf

[5] Nuit (2013), "Incident Management Procedures", Available http://www.it.northwestern.edu/bin/docs/servicemanager/NUIT-Incident-Management-Procedures.pdf

[6] H. Butterworth (2008), "Securing Intellectual Property: Protecting Trade Secrets and Other Information Assets (Information Security)", 1st Edition Information Security

[7] B. Wells (2011), "Automating a Manual Process" Available at http://weighlabel.com/2011/06/automating-amanual-process-things-to-consider/
[8] Brink (1996), "Sampling Method" Available at http://repository.up.ac.za/xmlui/bitstream/handle/2263/29 903/02 chapter3-5.pdf? sequence $=3 \&$ isAllowed $=y$

[9] J. Creswell (2003), "Research Design" Available at http://ucalgary.ca/paed/files/paed/2003_creswell_aframework-for-design.pdf

[10] K. Jansen, K. Corley, B. Jansen (2007), "E- Survey Methodology" Available https://faculty.ist.psu.edu/jjansen/academic/pubs/esurvey_ chapter_jansen.pdf

[11] R. Walker (2013), "IT Incident Management Framework \& Procedure" Available at http://www.flinders.edu.au/isdfiles/documents/CSC\%20form\%20library/IT\%20Incident $\% 20$ Management $\% 20$ Framework $\% 20 \& \% 20$ Procedure $\% 2$ 0V\%201_2.pdf 